\title{
Alteração química do solo irrigado por aspersão e gotejamento subterrâneo e superficial com água residuária ${ }^{1}$
}

\author{
Delvio Sandri' ${ }^{2}$ Edson E. Matsura ${ }^{3}$ \& Roberto Testezlaf ${ }^{3}$
}

\begin{abstract}
RESUMO
Propôs-se, neste trabalho, avaliar a variação dos constituintes químicos do solo devido à aplicação de água residuária e água de um depósito de fonte superficial, durante dois ciclos da alface (Lactuca sativa L.), cv "Elisa", utilizando-se os sistemas de irrigação por aspersão, gotejamento subterrâneo e superficial. Analisaram-se as camadas de solo de 0-0,10 e 0,10-0,20 m, aos 6, 26 e 46 dias após o transplantio no $1^{\circ}$ ciclo e aos 7, 27 e 49 dias após o transplantio, no $2^{\circ}$ ciclo. Os resultados demonstraram que no $1^{\circ}$ ciclo a concentração de sódio apresentou elevação nos tratamentos irrigados com água residuária, em ambas as camadas de solo. As concentrações de manganês e cobre também indicaram elevação nesse ciclo, para a camada de solo de 0-0,10 m na irrigação por aspersão e gotejamento superficial com água residuária; no $2^{\circ}$ ciclo os tratamentos irrigados com água residuária mostraram elevação do nitrogênio total em ambas as camadas de solo analisadas e da matéria orgânica, somente na camada de 0-0,10 m. Nesse ciclo, o manganês e o cobre também apresentaram redução na concentração, efeito atribuído às chuvas que ocorreram no período.
\end{abstract}

Palavras-chave: composição química do solo, efluente, Lactuca sativa L.

\section{Chemical alteration of soil irrigated by sprinkler, subsurface and surface drip irrigation with wastewater}

\begin{abstract}
The purpose of this study was to compare the variation of soil chemical constituents due to wastewater and surface water reservoir applications, during two cycles of the lettuce (Lactuca sativa L.), cv "Elisa", using sprinkler, surface and subsurface drip irrigation. The soil layers of $0-0.1 \mathrm{~m}$ and $0.1-0.2 \mathrm{~m}$ were analyzed, after 6, 26 and 46 days of transplanting in the $1^{\text {st }}$ cycle and after 7,27 and 49 days in the $2^{\text {nd }}$ cycle. The results showed an elevation of sodium concentration in the $1^{\text {st }}$ cycle for the treatments irrigated with wastewater in both soil layers. The manganese and copper concentrations increased in the $1^{\text {st }}$ cycle in the soil layer of $0-0.1 \mathrm{~m}$ for the sprinkler and surface drip irrigated with wastewater. In the $2^{\text {nd }}$ cycle the treatments with waste water presented an elevation of total nitrogen in both analyzed layers and for organic matter in the layer of $0-0.1 \mathrm{~m}$. Also in this cycle, a reduction in the manganese and copper concentrations was found, attributed to the rainfall that occurred in the period.
\end{abstract}

Key words: soil chemical composition, effluent, Lactuca sativa L.

1 Parte da Tese de Doutorado do primeiro autor. Pesquisa financiada pela FAPESP

2 Engenheiro Agrí́cola/UEG, BR 153, n 3.105, Fazenda Barreiro do Meio, CP 459, CEP 75110-390, Anápolis, GO. Fone: (62) 3328-1160. E-mail: sandri@ueg.br

3 FEAGRI/UNICAMP, CP 1160, CEP 13083-970, Campinas, SP. Fone: (19) 3788-1023. E-mail: matsura@agr.unicamp.br. Fone: (19) 3788-1024. E-mail: bob@agr.unicamp.br. 


\section{INTRODUÇÃO}

A aplicação de efluentes ao solo é vista como forma efetiva de controle da poluição e uma alternativa viável para aumentar a disponibilidade hídrica em regiões áridas e semiáridas, podendo reduzir os custos com tratamento e ainda servir como fonte de nutriente para as plantas reduzindo, assim, os custos, com a aquisição de fertilizantes químicos comerciais (Madeira et al., 2002; Hespanhol, 2003, Medeiros et al., 2005a); Esta técnica, porém, requer monitoramento do balanço de cátions no solo, como o sódio que, em geral, possui concentrações elevadas na água residuária, o que restringe a solubilidade de muitos nutrientes.

A irrigação com esgotos sanitários pode ser considerada uma fertirrigação devendo-se, portanto, observar todos os cuidados inerentes a tal prática. Embora o descarte indevido de efluente possa representar um problema ambiental, por outro lado apresenta características desejáveis, como potencial para fornecimento de nutrientes às plantas, principalmente nitrogênio, fósforo e potássio e, sobretudo, potencialidade de uso como fonte extra de água às plantas. Kiziloglu et al. (2008) afirma que a utilização de águas residuais para a irrigação é cada vez maior, sendo uma solução técnica para minimizar a degradação do solo e para restaurar o teor de nutrientes dos mesmos. Para Duarte et al. (2008) a irrigação com esgoto sem tratamento adequado pode ser nociva ao meio ambiente, à saúde humana, ao solo, aos aqüíferos e às culturas irrigadas; no entanto, segundo Heidarpour et al. (2007), a crescente necessidade de água nas regiões áridas do mundo, resultou na necessidade do uso de águas residuais para a aplicação da agricultura e paisagismo. Para Medeiros et al. (2005b) embora encontrada em abundância no Brasil, já apresenta comprometimento da sua quantidade e qualidade, principalmente nas regiões próximas aos grandes centros.

Em geral, os esgotos sanitários apresentam teores de macro e micronutrientes suficientes para o atendimento da demanda da maioria das culturas, razão por que o uso de água de esgoto doméstico pode apresentar de 200 a $400 \mathrm{mg} \mathrm{L}^{-1}$ de sais e $300 \mathrm{mg} \mathrm{L}^{-1}$ de sólidos dissolvidos inorgânicos. Silva et al. (2005) observaram, em esgotos domésticos tratados com reator UASB seguido de filtro biológico, presença de macro e micronutrientes suficientes para o crescimento da maioria das culturas cultivadas na região semi-árida.

De acordo com Adans et al. (1979), a aplicação em excesso de nitrogênio, fósforo e zinco, pode provocar carência de cobre, que aparece na forma de $\mathrm{Cu}^{2+}$, sendo adsorvido aos minerais de argila, hidróxido de ferro e à matéria orgânica, da mesma forma que altas concentrações de fósforo e molibdênio prejudicam sua absorção pelas plantas.

O nitrogênio amônia e o íon amônio, aplicados via fertilizantes ou lodo de esgoto em grande quantidade no solo, apresentam tendência a elevar a acidez do solo, pois a rápida nitrificação desses compostos libera íons de hidrogênio que permanecem adsorvidos pelos colóides do solo, ao mesmo tempo, é necessário verificar nutrientes facilmente lixiviáveis como o nitrogênio nitrato (Jnad et al., 2001).

Jnad et al. (2001), analisaram as alterações nas caracte- rísticas químicas do solo devidas à aplicação de efluente doméstico por gotejamento subterrâneo, em quatro diferentes localidades do Estado do Texas, observando elevação significativa de sódio no solo, em situações em que o teor inicial deste íon no efluente era alto (305 $\mathrm{mg} \mathrm{L}^{-1}$ ) e no solo era baixa. O fósforo aumentou significativamente próximo do emissor e na superfície do solo, pelo fato da linha de gotejadores estar instalada a uma pequena profundidade $(0,08 \mathrm{~m})$. O nitrogênio total, cálcio, magnésio, potássio, carbono orgânico total e conteúdo total de sais, não indicaram mudança significativa no perfil do solo.

Biscaro (2003) irrigou a alface americana durante 4 ciclos no mesmo local, utilizando o gotejamento superficial e subsuperficial para aplicação de água do Ribeirão Lavapés e observou, no primeiro ciclo, elevação do teor de fósforo, magnésio, zinco e boro na camada de solo dos canteiros; no segundo ciclo, o cálcio e o magnésio apresentaram pequenas variações de seus teores no solo, enquanto o zinco e o boro sofreram redução; nos terceiro e quarto ciclos, o cálcio e o magnésio apresentaram elevação de seus teores no solo e no quarto ciclo, o cobre, o ferro, o magnésio e o zinco reduziram seus teores no solo em relação ao terceiro ciclo.

Neilsen et al. (1989) aplicaram efluente secundário municipal com a irrigação por gotejamento, durante 4 anos, nas culturas de tomate, pimenta, cebola, pepino, feijão e melão, observando que o conteúdo de sódio nos primeiros $0,30 \mathrm{~m}$ de solo não foi prejudicial para as culturas. Na camada de solo de 0 - 0,15 m, ocorrem baixa variação do cálcio e magnésio e grande de sódio, enquanto o fósforo apresentou elevação devido à presença de derivados de detergentes nos efluentes utilizados.

Objetivou-se, neste trabalho, definir a variação dos constituintes químicos do solo durante dois ciclos da cultura da alface, em virtude da aplicação de água residuária tratada com leitos cultivados com macrófitas e água de um depósito de fonte superficial, utilizando-se os sistemas de irrigação por aspersão, gotejamento superficial e subterrâneo, nas camadas de solo de $0-0,10 \mathrm{~m}$ e $0,10-0,20 \mathrm{~m}$.

\section{MATERIAL E MÉTODOS}

O trabalho foi desenvolvido no Campo Experimental da Faculdade de Engenharia Agrícola da Universidade Estadual de Campinas, localizado no município de Campinas, SP, com Latitude de $22^{\circ} 53^{\prime} \mathrm{S}$ e Longitude de $47^{\circ} 05^{\prime} \mathrm{W}$. O solo foi classificado como Latossolo Vermelho Distroférrico. O clima, segundo a classificação de Köppen, é uma transição entre Cwa e Cwf, isto é, subtropical de altitude, seco no inverno e chuvoso e quente no verão, com precipitação média anual em torno de $1370 \mathrm{~mm}$, temperatura média anual de $21,7^{\circ} \mathrm{C}$ e umidade relativa do ar de $66,2 \%$. A textura do solo na camada de 0-0,20 m apresentou 56,9\% de argila, 19,2\% de silte e $23,9 \%$ de areia.

O desenvolvimento da pesquisa consistiu na realização de dois ciclos da cultura da alface (Lactuca sativa L.) cv Elisa, compreendendo os períodos de 08/06 a 23/07/01 ( ${ }^{\circ}$ ciclo) e de $17 / 08$ a $03 / 10 / 2001$ ( $2^{\circ}$ ciclo). 
A avaliação estatística foi realizada comparando-se os tratamentos, independentemente, em função das épocas de coleta das amostras de solo, que ocorreram aos 6, 26 e 46 dias após o transplantio - DAT para o $1^{\circ}$ ciclo, e aos 7, 27 e 49 dias após o transplantio para o $2^{\circ}$ ciclo. Nos dois ciclos, a primeira coleta de solo (6 e 7 DAT) foi realizada antes do início da aplicação de água residuária.

Utilizaram-se os sistemas de irrigação por aspersão e gotejamento subterrâneo e superficial e água de duas qualidades, ou seja, água residuária e água do depósito superficial, com três repetições, cujos tratamentos foram denominados: Ar - Aspersão, utilizando-se água residuária; Ad - aspersão, empregando-se água do depósito superficial; Gbr - gotejamento subterrâneo com água residuária; Gbd - gotejamento subterrâneo com água do depósito superficial; Gpr - gotejamento superficial com água residuária e Gpd - gotejamento superficial com água do depósito superficial.

$\mathrm{O}$ espaçamento entre as plantas de alface foi de $0,25 \mathrm{x}$ 0,25 m (16 plantas por $\left.\mathrm{m}^{2}\right)$, no total de quatro linhas de planta por canteiro (Lisbão et al., 1990). A aplicação de água para a cultura foi diária, às 17 h e 30 min, determinando-se a lâmina a partir da evapotranspiração de referência do dia anterior, obtida pela equação de Penman Monteith e fornecida por uma estação climática automática, instalada a $150 \mathrm{~m}$ do local do experimento.

Para cada sistema de irrigação foram construídos 3 canteiros, com 1,20 m de largura, 10,0 m de comprimento e 0,2 m de altura, no mesmo local durante os dois ciclos da cultura. No gotejamento subterrâneo e superficial se instalaram duas linhas de gotejadores CarboDrip tipo labirinto por canteiro, em que no gotejamento subterrâneo as mesmas foram enterradas a uma profundidade de $0,10 \mathrm{~m}$. O espaçamento entre emissores na linha lateral era de $0,40 \mathrm{~m}$ com vazão nominal de 2,3 $\mathrm{L} \mathrm{h}^{-1}$. Na irrigação por aspersão se instalaram 4 aspersores setoriais, com vazão nominal de $450 \mathrm{~L} \mathrm{~h}^{-1}$ e dispostos de $12 \times 12 \mathrm{~m}$.

No momento da confecção dos canteiros foram incorporados, na camada de $0-0,20 \mathrm{~m}$, tanto no $1^{\circ}$ como no $2^{\circ}$ ciclo, $33 \mathrm{~kg} \mathrm{ha}^{-1}$ de $\mathrm{N}, 116 \mathrm{~kg} \mathrm{ha}^{-1}$ de $\mathrm{P}_{2} \mathrm{O}_{5}$ e $67 \mathrm{~kg} \mathrm{ha}^{-1}$ de $\mathrm{K}_{2} \mathrm{O}$, considerando-se a recomendação de Trani \& Raij (1997) e mais 20,8 toneladas por ha de um condicionador de solo à base de turfa, o qual apresenta alto teor de matéria orgânica, contendo nitrogênio e magnésio em sua composição, apresentando condutividade elétrica (1:2 base volume) entre 0,5 e 1,3 dS m${ }^{-1}$ e $\mathrm{pH}$ entre 5,5 e 6,2. Em cobertura foram aplicados, por vez, $15 \mathrm{~g} \mathrm{~m}^{-2}$ de sulfato de amônia com $20 \%$ de N, aos 20 e 32 dias após o transplantio (DAT) no $1^{\circ}$ ciclo e aos 10,20 e 32 DAT no $2^{\circ}$ ciclo. Como cobertura morta se utilizou uma camada com espessura de 0,01 a 0,02 m de bagaço de cana-de-açúcar moído; constatou-se, no $1^{\circ}$ ciclo, uma precipitação de $40 \mathrm{~mm}$, concentrada na última semana antes do final do mesmo, enquanto no $2^{\circ}$ ciclo foi de $197 \mathrm{~mm}$.

O solo nas camadas de $0-0,10 \mathrm{~m}$ e $0,10-0,20 \mathrm{~m}$, foi analisado retirando-se amostras no início, no meio e no final de cada canteiro, que foram misturadas e resultaram em três amostras compostas (uma por canteiro) por camada analisada. O local de coleta das amostras de solo no canteiro foi sempre entre duas plantas de alface, em uma das linhas de plantas centrais consideradas úteis.

Os constituintes químicos analisados no solo foram: fósforo, potássio, sódio, nitrogênio total, manganês, cobre, cálcio, magnésio, enxofre, condutividade elétrica, matéria orgânica e capacidade de troca de cátions. A técnica de determinação analítica utilizada seguiu os procedimentos descritos por Silva (1999).

A Tabela 1 apresenta os dados de produtividade da alface observados nos $1^{\circ}$ e $2^{\circ}$ ciclos para os sistemas de irrigação por aspersão, gotejamento subterrâneo e superficial, utilizando-se água residuária e do depósito superficial.

Tabela 1. Produtividade da alface aos 46 DAT no $1^{\circ}$ ciclo e aos 49 DAT no $2^{\circ}$ ciclo para os três sistemas de irrigação e as duas qualidades da água

\begin{tabular}{ccccccc}
\hline \multirow{2}{*}{ Ciclo } & \multicolumn{5}{c}{ Produtividade (g m $\mathbf{~}^{-2}$ ) } \\
\cline { 2 - 7 } & Ar & Ad & Gbr & Gbd & Gpr & Gpd \\
$1^{0}$ & 2472,5 & 2383,3 & 4055,6 & 2848,0 & 3934,6 & 3290,0 \\
$2^{0}$ & 4238,2 & 3751,6 & 4792,2 & 3021,2 & 4528,5 & 3274,4 \\
\hline
\end{tabular}

Ar - Aspersão com água residuária, Ad - aspersão com água do depósito, Gbr - gotejamento subterrâneo com água residuária, Gbd - gotejamento subterrâneo com água do depósito, Gpr gotejamento superficial com água residuária e Gpd - gotejamento superficial com água do depósito. DAT - Dias após o transplantio

A produtividade da alface nos dois ciclos foi mais elevada nos sistemas de irrigação por gotejamento subterrâneo e superficial utilizando-se água residuária, quando comparada com o uso de água do depósito.

\section{RESULTADOS E DISCUSSÃO}

A Tabela 2 apresenta os valores médios dos parâmetros de qualidade da água residuária e água do depósito superficial, aplicadas pela irrigação por aspersão, gotejamento subterrâneo e superficial, durante os $1^{\circ}$ e $2^{\circ}$ ciclos.

A água residuária mostrou valores máximos de Ca de $36,5 \mathrm{mg} \mathrm{L}^{-1}$ (6 DAT no $1^{\circ}$ ciclo) e mínimo de $28,5 \mathrm{mg} \mathrm{L}^{-1}$ (10 DAT no $2^{\circ}$ ciclo), enquanto para o Na o máximo foi de $19,5 \mathrm{mg} \mathrm{L}^{-1}$ (25 DAT no $2^{\circ}$ ciclo) e o mínimo de $16,5 \mathrm{mg} \mathrm{L}^{-1}$ (6 DAT no $1^{\circ}$ ciclo); esses valores são menores que os encontrados por Miranda (1995), que observou concentração média de Na de 68,1 mg L-1 em água residuária com tratamento secundário. O teor de $\mathrm{Mg}$ variou entre 2,0 e 3,0 $\mathrm{mg} \mathrm{L}^{-1}$, sendo os teores normais para a irrigação, de acordo com Ayers \& Westcot (1991), de 0-20,0 $\mathrm{mg} \mathrm{L}^{-1}$ para o Ca, 0-40,0 $\mathrm{mg} \mathrm{L}^{-1}$ para o $\mathrm{Na}$ e entre $0-5,0 \mathrm{mg} \mathrm{L}^{-1}$ para o Mg. Segundo esta classificação, os teores de Ca na água residuária foram maiores que o permitido para a água de irrigação. Segundo Crook (1991) e Trani (2001), os valores máximos de Na na água de irrigação devem estar entre 50 a $70 \mathrm{mg} \mathrm{L}^{-1}$; assim, a água utilizada não deverá causar dano algum à cultura nem ao solo. Valores maiores que os indicados pelos autores podem ocasionar a existência excessiva deste íon, especialmente quando a umidade for inferior a $30 \%$ para qualquer tipo de solo.

Na água do depósito superficial os maiores valores observados de $\mathrm{Na}$ e Ca foram de 2,0 e 7,5 $\mathrm{mg} \mathrm{L}^{-1}$, respectivamente, 
Tabela 2. Qualidade da água residuária e do depósito superficial utilizada na irrigação por aspersão, gotejamento subterrâneo e superficial aos 6, 26 e 46 DAT do $1^{\circ}$ ciclo e aos 10, 25 e 47 DAT no $2^{\circ}$ ciclo

\begin{tabular}{|c|c|c|c|c|c|c|c|c|c|c|c|c|}
\hline \multirow{4}{*}{ Parâmetros } & \multicolumn{6}{|c|}{$1^{0}$ ciclo } & \multicolumn{6}{|c|}{$2^{0}$ ciclo } \\
\hline & \multicolumn{3}{|c|}{ Água residuária } & \multicolumn{3}{|c|}{ Água do depósito } & \multicolumn{3}{|c|}{ Água residuária } & \multicolumn{3}{|c|}{ Água do depósito } \\
\hline & 6 & 26 & 46 & 6 & 26 & 46 & 10 & 25 & 47 & 10 & 25 & 47 \\
\hline & \multicolumn{12}{|c|}{$\mathrm{mg} \mathrm{L}^{-1}$} \\
\hline $\mathrm{Na}$ & 16,5 & 18,0 & 19,0 & 1,0 & 2,0 & 2,0 & 18,0 & 19,5 & 18,5 & 2,0 & 2,0 & 1,0 \\
\hline $\mathrm{Ca}$ & 36,5 & 29,0 & 31,5 & 7,5 & 4,5 & 5,5 & 28,5 & 30,0 & 30,5 & 4,5 & 3,5 & 4,0 \\
\hline $\mathrm{Mg}$ & 2,0 & 2,5 & 2,0 & 1,5 & 2,0 & 2,0 & 2,5 & 2,0 & 3,0 & 2,0 & 2,0 & 2,0 \\
\hline RAS & 3,8 & 4,6 & 4,7 & 0,5 & 1,2 & 1,1 & 4,6 & 3,7 & 4,6 & 1,2 & 1,3 & 0,6 \\
\hline $\mathrm{Mn}$ & * & * & * & * & * & * & * & * & * & * & * & * \\
\hline$S$ & 2,0 & 2,5 & 2,0 & 1,0 & 1,0 & 1,0 & 2,5 & 3,0 & 4,0 & 1,0 & 1,0 & 2,5 \\
\hline $\mathrm{Fe}$ & 0,4 & 0,7 & 1,8 & 0,9 & 0,7 & 0,4 & 1,1 & 0,8 & 0,5 & 0,4 & 0,9 & 0,9 \\
\hline B & 0,1 & 0,1 & 0,1 & * & * & * & * & 0,1 & 0,1 & * & * & 0,3 \\
\hline K & 8,5 & 9,0 & 11,0 & 1,0 & * & 0,5 & 9,0 & 11,0 & 12,0 & 0,5 & 0,5 & 1,0 \\
\hline P total & 1,63 & 1,78 & 1,20 & 0,02 & 0,10 & 0,01 & 1,6 & 2,35 & 1,45 & 0,12 & 0,02 & 0,13 \\
\hline $\mathrm{P}_{2} \mathrm{O}_{5}$ & 3,68 & 4,13 & 2,70 & 0,04 & 0,22 & 0,03 & 3,41 & 5,35 & 1,83 & 0,27 & 0,05 & 0,32 \\
\hline $\mathrm{NH}_{4}^{+}-\mathrm{N}$ & 25,3 & 31,8 & 29,6 & 0,0 & 0,0 & 0,0 & 36,1 & 32,5 & 37,4 & 0,0 & 0,0 & 0,0 \\
\hline $\mathrm{NO}_{3}^{-}-\mathrm{N}$ & 0,4 & 0,1 & 0,5 & 0,3 & 0,0 & 0,4 & 0,8 & 1,2 & 0,3 & 0,3 & 0,4 & 0,2 \\
\hline DQO & 27,5 & 6,5 & 93,0 & 1,0 & 0,0 & 7,0 & 23,0 & 53,0 & 4,5 & 15,0 & 42,0 & 0,0 \\
\hline $\mathrm{SDT}^{1}$ & 323,80 & 287,05 & 332,15 & 33,9 & 25,0 & 32,7 & 329,3 & 331,9 & 400,0 & 34,3 & 30,4 & 30,7 \\
\hline $\mathrm{EC}\left(\mathrm{dS} \mathrm{m}^{-1}\right)$ & 0,51 & 0,45 & 0,52 & 0,05 & 0,04 & 0,05 & 0,52 & 0,52 & 0,63 & 0,06 & 0,05 & 0,05 \\
\hline $\mathrm{pH}$ & 7,3 & 7,4 & 7,1 & 6,6 & 7,2 & 6,9 & 7,2 & 7,4 & 7,4 & 6,9 & 7,1 & 6,9 \\
\hline
\end{tabular}

* Abaixo do limite de detecção; RAS - Razão de Absorção de Sódio; SDT - Sólidos Dissolvidos Totais; EC - Condutividade Elétrica; DQ0 - Demanda Química de Oxigênio); DAT - Dias após o transplantio ${ }^{1}$ Fonte: Paganini (1997), SDT $\left(\mathrm{mg} \mathrm{L}^{-1}\right)=\mathrm{EC}\left(\mathrm{dS} \mathrm{m}^{-1}\right) \times 640$

bem inferiores, portanto, aos observados na água residuária, as os teores de $\mathrm{Mg}$ foram muito semelhantes aos obtidos na água residuária e, desta forma, os teores de $\mathrm{Na}$, Ca e Mg, estão dentro dos limites aceitáveis para água de irrigação.

O valor da RAS (Tabela 2) considerando-se os dois ciclos, foi de no máximo 4,7 para a água residuária e de 1,3 para a água do depósito, semelhantes aos obtidos por Jnad et al. (2001), em efluentes oriundos de quatro localidades diferentes, variando entre 2,6 a 12,4. Tendo em vista a indicação de Ayers \& Westcot (1991), os valores observados neste trabalho não deverão causar efeitos negativos, que só passam a provocar algum dano às plantas para valores de RAS maiores que 10 .

Observaram-se valores de $\mathrm{NH}_{4}{ }^{+}-\mathrm{N}$ elevados na água residuária com o máximo de $31,8 \mathrm{mg} \mathrm{L}^{-1}$ aos $26 \mathrm{DAT}$ do $1^{\circ}$ ciclo e de $37,4 \mathrm{mg} \mathrm{L}^{-1}$ aos 47 DAT do $2^{\circ}$ ciclo; esses índices, de acordo com recomendação de Trani (2001), são considerados críticos para água de irrigação com fins à aplicação em hortaliças, porém para a maioria das outras culturas não ocorre efeito prejudicial com concentrações inferiores a 30,0 $\mathrm{mg} \mathrm{L}^{-1}$ (Ayers \& Westcot, 1991). Na água do depósito superficial se detectou a presença de $\mathrm{NH}_{4}{ }^{+}-\mathrm{N}$ em nenhum dos ciclos estudados.

Os parâmetros $\mathrm{S}, \mathrm{Fe}, \mathrm{B}, \mathrm{K}, \mathrm{P}$ total, $\mathrm{P}_{2} \mathrm{O}_{5}, \mathrm{NO}_{3}{ }^{-}-\mathrm{N}$, DQO, SDT, EC e pH, apresentaram valores dentro dos níveis aceitáveis para água de irrigação.

Apresenta-se, a seguir, uma discussão referente aos resultados dos constituintes químicos do solo, ocasião em que se analisou cada sistema de irrigação, independentemente, em função das épocas de coleta de amostra de solo, para as camadas de 0 - 0,10 m e 0,10 - 0,20 m.

Fósforo (P): O teor de $\mathrm{P}$ apresentou elevação significativa a nível de $10 \%$ de significância para o tratamento Ad no $1^{\circ}$ ciclo, dos 6 aos 46 DAT para as duas camadas de solo analisadas (Tabela 3). Nos tratamentos Gbr, Gbd, Gpr e Gpd no $1^{\circ}$ ciclo e em ambas as camadas de solo, embora não se tenha observado variação significativa, de maneira geral o teor de $\mathrm{P}$ se elevou até os 26 DAT, reduzindo aos 46 DAT em relação aos valores de 6 DAT, podendo ter sido influenciado pela absorção deste íon pela alface na segunda metade de seu ciclo; resultados concordantes com os obtidos nos tratamentos em que se utilizou água residuária foram observados por Duarte et al. (2008), quando do uso de efluente doméstico tratado e aplicado por gotejamento no cultivo da variedade de pimentão matador, não constatando alteração significativa nas concentrações de fósforo do solo. Cavallet et al. (2006) constataram a disponibilização do fósforo, em conseqüência da incorporação de 320 t ha ${ }^{-1}$ de água residuária, correção da acidez e insolubilização dos teores de alumínio trocável no solo no cultivo do milho.

Nota-se, ainda, uma mudança não regular dos valores de $\mathrm{P}$ entre as épocas de coleta de solo, em ambas as camadas analisadas, que pode ser atribuída ao fato de não se ter considerado a posição de coleta das amostras de solo em relação ao gotejador e, sim, somente em relação à linha de gotejadores que em virtude da baixa mobilidade no solo Costa et al. (2009), a variação espacial pode interferir no teor de P, conforme demonstrado por Jnad et al. (2001).

Esses autores relatam que o $\mathrm{P}$ indica tendência em permanecer próximo ao local de aplicação, por apresentar rápida precipitação e reação de adsorção no solo, sendo os principais responsáveis pela retenção do $\mathrm{P}$, a matéria orgânica e a ligação com íons e óxidos (Fe e $\mathrm{Al}$ ), porém o P se desloca para locais distantes do ponto de aplicação, quando sua capacidade de adsorção for atingida, podendo o movimento do íon ser influenciado pela umidade do 
Tabela 3. Valores médios de fósforo, potássio, sódio, nitrogênio total, manganês e cobre para a irrigação com aspersão, gotejamento subterrâneo e superficial utilizando-se água residuária e do depósito superficial, para três épocas de coleta de amostra e duas camadas de solo

\begin{tabular}{|c|c|c|c|c|c|c|c|c|c|c|c|c|c|}
\hline \multirow{2}{*}{$\begin{array}{l}\text { Coleta } \\
\text { em DAT }\end{array}$} & \multicolumn{6}{|c|}{$1^{0}$ ciclo } & \multirow{2}{*}{$\begin{array}{l}\text { Coleta } \\
\text { em DAT }\end{array}$} & \multicolumn{6}{|c|}{$2^{0}$ ciclo } \\
\hline & Ar & Ad & Gbr & Gbd & Gpr & Gpd & & $\mathrm{Ar}$ & Ad & Gbr & Gbd & Gpr & Gpd \\
\hline \multicolumn{14}{|c|}{ Camada 0 - 0,10 m Fósforo $\left(\mathrm{mg} \mathrm{dm}^{-3}\right)$} \\
\hline 6 & $47,7 \mathrm{a}$ & $33,0 \mathrm{~b}$ & $55,7 \mathrm{a}$ & $32,3 \mathrm{a}$ & $48,3 \mathrm{a}$ & $40,3 \mathrm{a}$ & 7 & $44,3 \mathrm{a}$ & $54,3 \mathrm{a}$ & $59,7 \mathrm{a}$ & $33,3 \mathrm{a}$ & $55,0 \mathrm{a}$ & $54,7 \mathrm{a}$ \\
\hline 26 & $52,3 \mathrm{a}$ & $47,3 \mathrm{ab}$ & $57,3 \mathrm{a}$ & $33,3 \mathrm{a}$ & $40,7 \mathrm{a}$ & $57,0 \mathrm{a}$ & 27 & $61,7 \mathrm{a}$ & $52,3 \mathrm{a}$ & $63,7 \mathrm{a}$ & $41,0 \mathrm{a}$ & $49,3 \mathrm{a}$ & $46,3 \mathrm{a}$ \\
\hline 46 & $44,3 \mathrm{a}$ & 56,7 a & $50,0 \mathrm{a}$ & $34,3 \mathrm{a}$ & $60,7 \mathrm{a}$ & $46,0 \mathrm{a}$ & 49 & $42,3 \mathrm{a}$ & $42,7 \mathrm{a}$ & $63,3 \mathrm{a}$ & $36,3 \mathrm{a}$ & $48,0 \mathrm{a}$ & $48,3 \mathrm{a}$ \\
\hline \multicolumn{14}{|c|}{ Camada $0,10-0,20 \mathrm{~m}$} \\
\hline 6 & $39,0 \mathrm{a}$ & $32,0 \mathrm{~b}$ & $50,3 \mathrm{a}$ & $36,0 \mathrm{a}$ & $41,3 \mathrm{a}$ & $35,7 \mathrm{a}$ & 7 & $51,3 \mathrm{a}$ & $42,7 \mathrm{a}$ & $59,7 \mathrm{a}$ & $25,0 \mathrm{a}$ & $41,7 \mathrm{a}$ & $47,0 \mathrm{a}$ \\
\hline 26 & $45,7 \mathrm{a}$ & $40,3 \mathrm{ab}$ & $56,7 \mathrm{a}$ & $25,7 \mathrm{a}$ & $49,7 \mathrm{a}$ & $44,0 \mathrm{a}$ & 27 & $54,3 \mathrm{a}$ & $42,3 \mathrm{a}$ & $56,7 \mathrm{a}$ & $24,7 \mathrm{a}$ & $42,0 \mathrm{a}$ & $39,7 \mathrm{a}$ \\
\hline 46 & $40,3 \mathrm{a}$ & $53,0 \mathrm{a}$ & $50,7 \mathrm{a}$ & $35,0 \mathrm{a}$ & $40,7 \mathrm{a}$ & $51,0 \mathrm{a}$ & 49 & $54,3 \mathrm{a}$ & $48,3 \mathrm{a}$ & $62,0 \mathrm{a}$ & $31,3 \mathrm{a}$ & $55,0 \mathrm{a}$ & $40,0 \mathrm{a}$ \\
\hline \multicolumn{14}{|c|}{ Camada 0 - 0,10 m Potássio $\left(\mathrm{cmol} \mathrm{dm}^{-3}\right)$} \\
\hline 6 & $0,38 \mathrm{a}$ & $0,49 \mathrm{~b}$ & $0,49 \mathrm{a}$ & $0,45 \mathrm{a}$ & $0,43 \mathrm{a}$ & $0,63 \mathrm{a}$ & 7 & $0,33 \mathrm{a}$ & $0,70 \mathrm{a}$ & $0,39 a$ & $0,40 \mathrm{a}$ & $0,40 \mathrm{a}$ & $0,40 \mathrm{a}$ \\
\hline 26 & $0,37 \mathrm{a}$ & $0,72 \mathrm{a}$ & $0,43 \mathrm{a}$ & $0,44 \mathrm{a}$ & $0,51 \mathrm{a}$ & $0,46 \mathrm{a}$ & 27 & $0,30 \mathrm{a}$ & $0,60 a b$ & $0,40 \mathrm{a}$ & $0,40 \mathrm{a}$ & $0,40 \mathrm{a}$ & $0,40 \mathrm{a}$ \\
\hline 46 & $0,33 \mathrm{a}$ & $0,70 \mathrm{a}$ & $0,36 \mathrm{a}$ & $0,41 \mathrm{a}$ & $0,45 \mathrm{a}$ & $0,44 \mathrm{a}$ & 49 & $0,17 \mathrm{~b}$ & $0,40 \mathrm{~b}$ & $0,30 \mathrm{a}$ & $0,20 \mathrm{~b}$ & $0,30 \mathrm{a}$ & $0,30 \mathrm{a}$ \\
\hline \multicolumn{14}{|c|}{ Camada 0,10-0,20 m } \\
\hline 6 & $0,34 \mathrm{a}$ & $0,44 \mathrm{~b}$ & $0,57 \mathrm{a}$ & $0,45 \mathrm{a}$ & $0,43 \mathrm{a}$ & $0,63 \mathrm{a}$ & 7 & $0,30 \mathrm{a}$ & $0,60 \mathrm{a}$ & $0,36 \mathrm{a}$ & $0,40 \mathrm{a}$ & $0,45 \mathrm{a}$ & $0,49 \mathrm{a}$ \\
\hline 26 & $0,40 \mathrm{a}$ & $0,65 a b$ & $0,42 a b$ & $0,45 \mathrm{a}$ & $0,52 \mathrm{a}$ & $0,49 \mathrm{a}$ & 27 & $0,30 \mathrm{a}$ & $0,60 \mathrm{a}$ & $0,39 a$ & $0,30 \mathrm{a}$ & $0,37 \mathrm{ab}$ & $0,40 \mathrm{~b}$ \\
\hline 46 & $0,39 \mathrm{a}$ & $0,68 \mathrm{a}$ & $0,38 \mathrm{~b}$ & $0,44 \mathrm{a}$ & $0,45 \mathrm{a}$ & $0,48 \mathrm{a}$ & 49 & $0,30 \mathrm{a}$ & $0,50 \mathrm{a}$ & $0,24 \mathrm{~b}$ & $0,30 \mathrm{a}$ & $0,33 \mathrm{~b}$ & $0,33 \mathrm{~b}$ \\
\hline \multicolumn{14}{|c|}{ Camada 0 - 0,10 m Sódio $\left(\mathrm{mg} \mathrm{dm}^{-3}\right)$} \\
\hline 6 & $7,0 \mathrm{~b}$ & $4,1 \mathrm{~b}$ & $6,0 \mathrm{~b}$ & $3,8 \mathrm{a}$ & $6,4 \mathrm{~b}$ & $5,2 \mathrm{a}$ & 7 & $12,2 \mathrm{~b}$ & $4,4 \mathrm{a}$ & $8,6 \mathrm{a}$ & $3,0 \mathrm{a}$ & 7,8 a & $3,4 \mathrm{a}$ \\
\hline 26 & $8,6 \mathrm{ab}$ & $4,8 \mathrm{ab}$ & $10,0 \mathrm{~b}$ & $3,7 \mathrm{a}$ & $8,5 a b$ & $6,8 \mathrm{a}$ & 27 & $10,5 \mathrm{~b}$ & $5,6 \mathrm{a}$ & $9,1 \mathrm{a}$ & $3,8 \mathrm{a}$ & $12,3 \mathrm{a}$ & $5,7 \mathrm{a}$ \\
\hline 46 & 14,3 a & $6,0 \mathrm{a}$ & $17,3 \mathrm{a}$ & $4,5 \mathrm{a}$ & $12,0 \mathrm{a}$ & $6,7 \mathrm{a}$ & 49 & $17,2 \mathrm{a}$ & $5,0 \mathrm{a}$ & $6,8 \mathrm{a}$ & $2,9 \mathrm{a}$ & $7,1 \mathrm{a}$ & $3,9 \mathrm{a}$ \\
\hline \multicolumn{14}{|c|}{ Camada $0,10-0,20 \mathrm{~m}$} \\
\hline 6 & 6,7 a & $4,6 \mathrm{a}$ & $6,3 \mathrm{c}$ & $4,7 \mathrm{a}$ & $7,9 \mathrm{~b}$ & $4,7 \mathrm{a}$ & 7 & $12,3 \mathrm{a}$ & $4,3 \mathrm{a}$ & 8,9 a & $3,6 \mathrm{a}$ & $9,4 \mathrm{a}$ & $3,7 \mathrm{a}$ \\
\hline 26 & $9,5 \mathrm{ab}$ & $6,4 a b$ & $11,9 \mathrm{~b}$ & $5,0 \mathrm{a}$ & $9,9 \mathrm{~b}$ & $5,7 \mathrm{a}$ & 27 & $11,8 \mathrm{a}$ & $4,8 \mathrm{a}$ & $9,0 \mathrm{a}$ & $3,8 \mathrm{a}$ & $14,5 \mathrm{a}$ & $4,4 \mathrm{a}$ \\
\hline 46 & $10,0 \mathrm{~b}$ & $7,3 \mathrm{~b}$ & $16,8 \mathrm{a}$ & $5,6 \mathrm{a}$ & $15,2 \mathrm{a}$ & $5,1 \mathrm{a}$ & 49 & $15,3 \mathrm{a}$ & $5,0 \mathrm{a}$ & $10,6 \mathrm{a}$ & $3,8 \mathrm{a}$ & $10,5 \mathrm{a}$ & $3,5 \mathrm{a}$ \\
\hline \multicolumn{14}{|c|}{ Camada 0 - 0,10 m Nitrogênio total $\left(\mathrm{cmol} \mathrm{dm}^{-3}\right)$} \\
\hline 6 & $1,8 \mathrm{~b}$ & $2,2 \mathrm{a}$ & $2,0 \mathrm{a}$ & $1,8 \mathrm{~b}$ & $1,8 \mathrm{~b}$ & $2,0 \mathrm{~b}$ & 7 & $2,9 \mathrm{ab}$ & $2,6 \mathrm{a}$ & $2,9 a b$ & $2,0 \mathrm{~b}$ & $2,4 a b$ & $3,0 \mathrm{a}$ \\
\hline 26 & $2,7 \mathrm{a}$ & $2,7 \mathrm{a}$ & $2,8 \mathrm{a}$ & $2,3 \mathrm{a}$ & $2,6 \mathrm{a}$ & $3,4 \mathrm{a}$ & 27 & $1,3 \mathrm{~b}$ & $2,4 \mathrm{a}$ & $2,0 \mathrm{~b}$ & $2,0 \mathrm{~b}$ & $2,0 \mathrm{~b}$ & $2,4 \mathrm{a}$ \\
\hline 46 & $2,6 \mathrm{a}$ & $2,4 \mathrm{a}$ & $2,6 \mathrm{a}$ & $2,6 \mathrm{a}$ & $2,8 \mathrm{a}$ & $3,2 \mathrm{a}$ & 49 & $3,5 \mathrm{a}$ & $3,2 \mathrm{a}$ & $4,4 \mathrm{a}$ & $3,5 \mathrm{a}$ & $3,4 \mathrm{a}$ & $2,6 \mathrm{a}$ \\
\hline \multicolumn{14}{|c|}{ Camada $0,10-0,20$ m } \\
\hline 6 & $1,5 \mathrm{~b}$ & $1,5 b$ & $2,4 \mathrm{a}$ & $2,4 \mathrm{a}$ & $1,8 \mathrm{~b}$ & $2,0 \mathrm{~b}$ & 7 & $2,0 a b$ & $1,8 \mathrm{~b}$ & $2,0 \mathrm{~b}$ & $1,1 \mathrm{~b}$ & $1,8 a b$ & $1,3 \mathrm{~b}$ \\
\hline 26 & $2,7 \mathrm{ab}$ & $3,0 \mathrm{a}$ & $2,1 \mathrm{a}$ & $3,5 \mathrm{a}$ & $2,8 \mathrm{a}$ & $3,2 \mathrm{a}$ & 27 & $1,1 \mathrm{~b}$ & $1,5 \mathrm{~b}$ & $1,3 \mathrm{~b}$ & $1,3 \mathrm{~b}$ & $1,3 \mathrm{~b}$ & $2,0 a b$ \\
\hline 46 & $3,0 \mathrm{a}$ & $2,4 a b$ & $2,8 \mathrm{a}$ & $3,0 \mathrm{a}$ & $2,8 \mathrm{a}$ & $3,0 \mathrm{a}$ & 49 & $3,0 \mathrm{a}$ & $2,8 \mathrm{a}$ & $4,1 \mathrm{a}$ & $2,6 \mathrm{a}$ & $2,8 \mathrm{a}$ & $2,8 \mathrm{a}$ \\
\hline \multicolumn{14}{|c|}{ Camada 0 - 0,10 m Manganês $\left(\mathrm{mg} \mathrm{dm}^{-3}\right)$} \\
\hline 6 & $26,9 \mathrm{~b}$ & $24,6 \mathrm{~b}$ & $32,7 \mathrm{a}$ & $24,9 \mathrm{a}$ & $32,0 \mathrm{~b}$ & 34,8 a & 7 & $34,4 \mathrm{a}$ & $53,5 \mathrm{a}$ & $42,2 \mathrm{a}$ & $31,6 \mathrm{a}$ & $48,1 \mathrm{a}$ & $30,2 \mathrm{a}$ \\
\hline 26 & $34,3 \mathrm{a}$ & $41,2 \mathrm{a}$ & $38,4 \mathrm{a}$ & $29,6 \mathrm{a}$ & $48,4 \mathrm{a}$ & $33,8 \mathrm{a}$ & 27 & $32,1 \mathrm{a}$ & $43,8 \mathrm{ab}$ & $38,2 \mathrm{a}$ & $28,8 \mathrm{ab}$ & $41,3 \mathrm{ab}$ & $37,2 \mathrm{a}$ \\
\hline 46 & $30,9 \mathrm{a}$ & $41,3 \mathrm{a}$ & $36,0 \mathrm{a}$ & $26,8 \mathrm{a}$ & $40,2 \mathrm{a}$ & $32,7 \mathrm{a}$ & 49 & $24,8 \mathrm{a}$ & $34,1 \mathrm{~b}$ & $30,2 \mathrm{a}$ & $21,4 \mathrm{~b}$ & $31,5 \mathrm{~b}$ & $28,7 \mathrm{a}$ \\
\hline \multicolumn{14}{|c|}{ Camada $0,10-0,20 \mathrm{~m}$} \\
\hline 6 & $27,7 \mathrm{a}$ & $23,8 \mathrm{~b}$ & $33,1 \mathrm{a}$ & $25,3 \mathrm{a}$ & $35,9 \mathrm{a}$ & $34,8 \mathrm{a}$ & 7 & $33,0 \mathrm{a}$ & $48,2 \mathrm{a}$ & $45,7 \mathrm{a}$ & $31,2 a$ & $54,7 \mathrm{a}$ & $34,7 \mathrm{a}$ \\
\hline 26 & $35,5 \mathrm{a}$ & $42,7 \mathrm{a}$ & $36,7 \mathrm{a}$ & $31,0 \mathrm{a}$ & $49,1 \mathrm{a}$ & $29,9 \mathrm{a}$ & 27 & $31,8 \mathrm{a}$ & $40,1 \mathrm{a}$ & $36,8 \mathrm{a}$ & $28,5 \mathrm{a}$ & $42,7 \mathrm{~b}$ & $34,8 \mathrm{a}$ \\
\hline 46 & $34,3 \mathrm{a}$ & $37,5 \mathrm{a}$ & $36,5 \mathrm{a}$ & $29,2 \mathrm{a}$ & $42,2 \mathrm{a}$ & $31,7 \mathrm{a}$ & 49 & $30,2 \mathrm{a}$ & $38,2 \mathrm{a}$ & $26,8 \mathrm{~b}$ & $20,3 \mathrm{~b}$ & $34,5 \mathrm{~b}$ & $26,8 \mathrm{a}$ \\
\hline \multicolumn{14}{|c|}{ Camada 0 - 0,10 m Cobre $\left(\mathrm{cmol} \mathrm{dm}^{-3}\right)$} \\
\hline 6 & $4,6 \mathrm{~b}$ & $5,4 \mathrm{~b}$ & $9,5 \mathrm{a}$ & $6,5 \mathrm{a}$ & $7,2 \mathrm{~b}$ & $5,1 \mathrm{c}$ & 7 & $5,1 \mathrm{a}$ & $5,6 \mathrm{a}$ & $10,2 \mathrm{a}$ & $6,3 \mathrm{a}$ & $7,5 \mathrm{a}$ & $6,2 \mathrm{a}$ \\
\hline 26 & $5,3 a b$ & $5,3 b$ & $9,5 \mathrm{a}$ & $6,5 \mathrm{a}$ & $7,7 \mathrm{ab}$ & $6,2 \mathrm{~b}$ & 27 & $5,0 \mathrm{a}$ & $5,4 \mathrm{a}$ & $10,3 \mathrm{a}$ & $6,3 \mathrm{a}$ & $7,5 \mathrm{a}$ & $7,0 \mathrm{a}$ \\
\hline 46 & $5,7 \mathrm{a}$ & $6,9 \mathrm{a}$ & $9,8 \mathrm{a}$ & $7,4 \mathrm{a}$ & $8,7 \mathrm{a}$ & $7,5 \mathrm{a}$ & 49 & $5,0 \mathrm{a}$ & $5,1 \mathrm{a}$ & $9,4 \mathrm{a}$ & $5,5 \mathrm{~b}$ & $6,6 \mathrm{~b}$ & $6,2 \mathrm{a}$ \\
\hline \multicolumn{14}{|c|}{ Camada $0,10-0,20$ m } \\
\hline 6 & $4,4 \mathrm{~b}$ & $5,5 \mathrm{a}$ & $9,6 \mathrm{a}$ & $6,3 \mathrm{a}$ & $7,4 \mathrm{a}$ & $5,1 \mathrm{~b}$ & 7 & $4,9 \mathrm{a}$ & $5,4 \mathrm{a}$ & $10,5 \mathrm{a}$ & $6,3 \mathrm{a}$ & $7,8 \mathrm{a}$ & $6,4 \mathrm{a}$ \\
\hline 26 & $5,2 a b$ & $5,3 \mathrm{a}$ & $8,7 \mathrm{a}$ & $7,7 \mathrm{a}$ & $9,2 \mathrm{a}$ & $6,4 \mathrm{a}$ & 27 & $5,0 \mathrm{a}$ & $5,3 \mathrm{a}$ & $10,1 \mathrm{a}$ & $6,5 \mathrm{a}$ & $7,6 \mathrm{a}$ & $6,8 \mathrm{a}$ \\
\hline 46 & $5,8 \mathrm{a}$ & $6,0 \mathrm{a}$ & $9,7 \mathrm{a}$ & $7,3 \mathrm{a}$ & $8,3 \mathrm{a}$ & $7,2 \mathrm{a}$ & 49 & $6,5 \mathrm{a}$ & $5,1 \mathrm{a}$ & $7,6 \mathrm{~b}$ & $6,6 \mathrm{a}$ & $6,7 \mathrm{a}$ & $5,9 \mathrm{a}$ \\
\hline
\end{tabular}

Médias seguidas de letras distintas na coluna diferem entre si a nível de $10 \%$ de significância

$\mathrm{Ar}$ - Aspersão com água residuária, Ad - aspersão com água do depósito, Gbr - gotejamento subterrâneo com água residuária, Gbd - gotejamento subterrâneo com água do depósito, Gpr - gotejamento superficial com água residuária e Gpd - gotejamento superficial com água do depósito. DAT - Dias após o transplantio

solo;eles constataram, também que o $\mathrm{P}$ a $0,08 \mathrm{~m}$ acima do gotejador foi maior que na área de controle, apresentando diferença significativa enquanto a $0,30 \mathrm{~m}$ abaixo do mesmo, não observaram diferença significativa, fato este também comprovado por Miranda (1995), ao constatar, em um ensaio realizado em colunas de solo, que 99,5\% do total de $\mathrm{P}$ presente na água de irrigação ficaram retidos no solo, em que o principal responsável é a matéria orgânica ou o próprio material coloidal do solo.

Potássio (K): Observa-se, no $1^{\circ}$ ciclo, redução significativa no teor de $\mathrm{K}$ na camada de solo de 0,10 - 0,20 m para o tratamento Gbr dos 6 aos 46 DAT e elevação significativa no tratamento Ad em ambas as camadas de solo (Tabela 3); no $2^{\circ}$ ciclo deu-se redução significativa no teor de $\mathrm{K}$ dos 7 
aos 49 DAT na camada de solo de 0-0,10 m para os tratamentos Ar, Ad e Gbd, chegando a 100\% neste último, enquanto na camada de solo de $0,10-0,20 \mathrm{~m}$, a redução significativa ocorreu nos tratamentos Gbr, Gpr e Gpd. Duarte et al. (2008), ao contrário, não observaram alteração significativa nas concentrações de potássio e $\mathrm{pH}$ do solo quando da aplicação de água residuária doméstica. Para Costa et al. (2009), a difusão e a absorção de potássio são favorecidas pela manutenção de alta concentração deste nutriente na solução do solo e pela ausência de impedimentos físico e químico, fatores que podem ter influenciado nos resultados obtidos.

De modo geral, no $2^{\circ}$ ciclo houve tendência de redução mais acentuada em relação ao $1^{\circ}$ ciclo, com fortes evidências de que, em parte, podem ter havido influência na lixiviação devido às chuvas mais intensas verificadas neste ciclo, que totalizaram $197 \mathrm{~mm}$, comparadas com a precipitação de apenas $40 \mathrm{~mm}$ no $1^{\circ}$ ciclo, juntamente com a lixiviação da própria água de irrigação, o que pode ser confirmado considerando-se que os dois ciclos foram realizados no mesmo local e os experimentos foram realizados de forma idêntica. Miranda (1995) também observou redução de K (24,5\%) na análise do solo após um ciclo da cultura da alface. Baumgartner et al. (2007), por sua vez, encontraram elevação no teor de $\mathrm{K}$, sendo de $0,12 \mathrm{cmol} \mathrm{dm}^{-3}$ antes e de $1,78,1,67$, 1,40 e $0,94 \mathrm{cmol} \mathrm{dm}^{-3}$ depois de um ciclo da cultura da alface para os tratamentos: alface irrigada com água de origem subterrânea, e adubação suplementar; alface irrigada com água residuária de viveiro de peixes alimentados com ração; alface irrigada com água residuária originária de lagoa de estabilização de dejetos de suínos, e água de lagoa de cultivo de algas, alimentada com resíduo de biodigestor de dejeto de suíno, respectivamente.

Sódio (Na): O Na foi o parâmetro químico que apresentou maior elevação de seu teor no solo, dos 6 aos 46 DAT no $1^{\circ}$ ciclo, observando-se diferença significativa nos tratamentos Ar, Ad, Gbr e Gpr em ambas as camadas de solo; no $2^{\circ}$ ciclo, apenas o tratamento Ar mostrou elevação significativa dos 7 e 27 DAT em relação aos 49 DAT para a camada de solo e 0-0,10 m (Tabela 3). O sódio é um dos parâmetros que mais interfere no ter de sais no solo, como observado por Cerqueira et al. (2008), quando do uso de uso de águas residuárias domésticas tratadas na irrigação por gotejamento de Heliconia psittacorum e Gladiolus hortulanus, principalmente na camada superficial do solo, após um ano de experimento.

No $1^{\circ}$ ciclo as maiores elevações de Na ocorreram nos tratamentos com água residuária, chegando a $188 \%$ no Gbr para a camada de solo de $0-0,10 \mathrm{~m}$ e de $166 \%$ na camada de 0,10-0,20 m; referidas elevações podem ser atribuídas à grande quantidade deste íon na água residuária $\left(19,0 \mathrm{mg} \mathrm{L}^{-1}\right.$ para o $1^{\circ}$ ciclo). A elevação no teor de $\mathrm{Na}$, simultaneamente com a redução de Ca e Mg no solo, poderá provocar alterações nas propriedades físicas do solo, principalmente a expansão e a dispersão da argila, reduzindo a porosidade e, em consequência, a condutividade hidráulica (Jnad et al., 2001). Quando a relação de sódio com outros cátions, sobretudo o cálcio e magnésio, é muito elevada (>26), o sódio tende a substituir os íons de cálcio e magnésio nas partículas de solo, diminuindo sua permeabilidade, que deve-se a dispersão dos agregados solo, o que eleva o volume de microporos e a capacidade de retenção de água do mesmo (Lima et al., 1990).

Nesse mesmo ciclo notou-se tendência de elevação progressiva de Na nas três épocas de coleta de solo (6, 26 e 46 DAT) em todos os tratamentos e nas duas camadas de solo; concluiu-se que pode ter ocorrido que os teores de $\mathrm{Na}$ presente na água residuária tenham sido superiores à capacidade de absorção pela alface, promovendo acúmulo deste íon no solo, independente do sistema de irrigação, sendo mais evidente no $1^{\circ}$ ciclo que no $2^{\circ}$, em que a lixiviação foi pouca ou nenhuma, tanto pela água de irrigação como pela precipitação natural. Resultados semelhantes foram obtidos por Medeiros et al. (2005) relatando que, mesmo havendo maiores concentrações de $\mathrm{Na}^{+}$no solo irrigado com água residuária filtrada em comparação ao manejo convencional (adubação química e irrigação suplementar com água boa), não verificaram lixiviações, indicando que a aplicação controlada pode ser uma alternativa para potencializar a produção de alimentos; observaram, ainda, que a aplicação de água residuária elevou a concentração de $\mathrm{Na}^{+}$no solo nas profundidades de 0-0,10 m e 0,10-0,20 m; todavia, decresceu significativamente nas profundidades de 0,20-0,40 m; 0,40-0,50 m e 0,50-0,60 m).

Nitrogênio Total (NT): Observou-se, no $1^{\circ}$ ciclo, aumento significativo na concentração de NT, dos 6 aos 46 DAT nos tratamentos Ar, Gbd, Gpr e Gpd na camada de solo de 0-0,10 m e nos tratamentos Ar, Ad, Gpr e Gpd na camada de solo de 0,10-0,20 m (Tabela 3). Medeiros et al. (2005) ao contrário, não detectaram aumentos nas concentrações de NT com a aplicação de água residuária doméstica bruta, filtrada com filtro de areia e de disco e aplicada por gotejamento durante o período de 270 dias.

De acordo com von Sperling (1996) a elevação dos teores de nitrogênio em camadas de solo mais profundas se deve ao fato de que o NT em efluentes domésticos que normalmente está na faixa de 15 a $50 \mathrm{mg} \mathrm{L}^{-1}$, em que aproximadamente $60 \%$ se apresentam na forma de amônia e o restante na forma orgânica; assim, quando o mesmo atinge o solo, o $\mathrm{NH}_{4}{ }^{+}$é rapidamente oxidado para a forma $\mathrm{NO}_{3}{ }^{-}$ que, por sua vez, apresenta alta capacidade de lixiviação pelo perfil do solo.

No $2^{\circ}$ ciclo a elevação foi significativa dos 27 aos 49 DAT nos tratamentos Ar, Gbr, Gbd e Gpr na camada de solo de 0-0,10 m; já na camada de solo de 0,10-0,20 m, este mesmo comportamento foi observado nos tratamentos Ar, Ad, Gbr, Gbd, e Gpr e, para a camada mais profunda de solo, constatou-se elevação significativa dos 7 aos 49 DAT para os tratamentos Ad, Gbr, Gbd e Gpd. As elevações de NT, seja no $1^{\circ}$ ou no $2^{\circ}$ ciclos, são devidas à grande quantidade de $\mathrm{N}$ na água de irrigação como pela aplicação em cobertura de sulfato de amônia.

Nota-se que os tratamentos com elevação mais acentuada de NT no $2^{\circ}$ ciclo foram o Gbr com $105 \%$ e Gbd com $136 \%$ na camada de solo de 0,10-0,20 m, que pode ser atribuído ao fato da aplicação da água ter sido realizada diretamente sobre esta camada ou lixiviação de parte deste íon da cama- 
da superficial para a mais profunda. Jnad et al. (2001) aplicando água residuária observaram que próximo ao emissor, houve elevação significativa do NT quando comparada com a área de controle.

Manganês (Mn): $\mathrm{O}$ teor do $\mathrm{Mn}$ do solo durante o $1^{\circ}$ ciclo apresentou elevação significativa dos 6 aos 46 DAT mas apenas no tratamento Ad, em ambas as camadas de solo analisadas. Os tratamentos Ar, Gbr, Gbd e Gpr, só apresentaram tendência de aumento no teor de Mn, porém de forma não significativa, sendo maiores nas amostras realizadas aos 26 DAT e diminuindo aos 46 DAT permanecendo, no entanto, acima dos valores observados aos 6 DAT (Tabela 3).

No $2^{\circ}$ ciclo foi notória uma redução dos 7 aos 49 DAT nos tratamentos Ad, Gbd e Gpr para a camada de solo de 0 - 0,10 m e nos tratamentos Gbr, Gbd e Gpr na camada de 0,10 - 0,20 m. Com exceção do tratamento Gpd para o $1^{\circ}$ ciclo e na camada de solo de 0 - 0,10 m, os demais apresentaram tendência de diminuição progressiva do teor de Mn entre as épocas de amostragem de 7, 27 e 49 DAT, em ambas as camadas de solo. Acredita-se que a inclinação de diminuição progressiva do $\mathrm{Mn}$ no $2^{\circ}$ ciclo tenha sido influenciada, possivelmente, pela absorção pelas plantas, uma vez que em ambos os tipos de água o teor de Mn sempre se manteve abaixo do limite de detecção do equipamento utilizado nas análises. A disponibilidade do Mn no solo depende sobretudo do $\mathrm{pH}$, do potencial de oxi-redução, da matéria orgânica e do equilibro com outros cátions, como o ferro, cálcio e magnésio. Segundo Borkert et al. (2001) fatores ambientais (umidade e temperatura), exercem grande influência na solubilidade do $\mathrm{Mn}$.

Cobre (Cu): Notou-se que no $1^{\circ}$ ciclo o teor de Cu elevou-se significativamente dos 6 aos 46 DAT, para a Ar, Ad, Gpr e Gpd na camada de 0 - 0,10 m e nos tratamentos Ar e Gpd na camada de solo de 0,10 - 0,20 m; nos demais tratamentos houve apenas tendência de elevação, enquanto no $2^{\circ}$ ciclo o teor de $\mathrm{Cu}$ teve elevação significativa dos 7 aos 49 DAT, para os tratamentos Gbd e Gpr na camada de solo de $0-0,10 \mathrm{~m}$ e nos demais tratamentos a tendência foi apenas de redução em ambas as camadas de solo, com exceção do tratamento Ar, na camada de 0,10 - 0,20 m que teve elevação (Tabela 3).

Existem fortes evidências de que a tendência de redução no teor de cobre no $2^{\circ}$ ciclo, a exemplo do que ocorreu com os parâmetros $\mathrm{Na}, \mathrm{Mn}, \mathrm{S}$ e CTC, seja devida às chuvas mais intensas durante o ciclo, provocando lixiviação de parte deste íon, uma vez que o local do experimento nos dois ciclos foi o mesmo e a qualidade da água utilizada na irrigação era semelhante. Fator como o pH, pode ter exercido influência no comportamento do cobre, pois dificulta sua elevação e pode ainda interagir com o potássio, zinco, nitrogênio e fósforo, interferindo na sua disponibilidade.

Cálcio (Ca): O teor de Ca do solo no $1^{\circ}$ ciclo teve elevação significativa dos 6 aos 46 DAT, somente no tratamento Ad, em ambas as camadas de solo. Nos tratamentos Ar, Gbr e Gpd na camada de 0 - 0,10 m e nos tratamentos Gbr e Gpd na camada de 0,10 - 0,20 m dos 6 aos 46 DAT, houve tendência apenas de diminuição no teor de Ca não apresentando, porém, diferença significativa, verificando-se o mesmo ocorrendo para os tratamentos Gbr e Gpr em ambas as camadas de solo, no $2^{\circ}$ ciclo (Tabela 4).

Conforme Jnad et al. (2001), a redução no teor de Ca no solo pode ser devida à reação do Ca com carbonato e sulfato presentes em alta concentração em efluentes e em virtude, também, da sua precipitação; pode, ainda, ter ocorrido o deslocamento do cálcio, juntamente com o $\mathrm{Na}$, comportamento observado por este autor, quando analisou o solo acima do emissor, abaixo e no nível do mesmo, pois o íon Ca é conhecido como moderador da influência do Na sobre as propriedades físicas do solo.

Magnésio (Mg): Observa-se, no $1^{\circ}$ ciclo, elevação significativa no teor de $\mathrm{Mg}$ dos 6 aos 46 DAT no tratamento Ad em ambas as camadas de solo, sendo estas de $25 \%$; já no $2^{\circ}$ ciclo se constatou elevação significativa no teor de Mg somente no tratamento Ar, dos 7 as 49 DAT na camada de solo de 0,10 - 0,20 m, de 20\% (Tabela 4). Miranda (1995) por sua vez, encontrou um acréscimo de Mg de $25 \%$ durante um ciclo da cultura da alface, enquanto Jnad et al. (2001), constataram que o teor de $\mathrm{Mg}$ foi sempre mais elevado no solo irrigado com efluente com tratamento secundário que no solo controle, em todos os pontos analisados. Já Miranda et al. (2008), comparado água de rio com efluentes na irrigação de melão aplicada por gotejamento, observaram redução dos e os teores de cálcio e magnésio do solo e aumento da taxa de sódio trocável.

Enxofre (S): Observou-se, durante o $1^{\circ}$ ciclo, elevação significativa no teor de $S$ na analise realizada aos 26 DAT em relação aos 6 e 46 DAT na camada de 0 - 0,10 m (Tabela 4); no $2^{\circ}$ ciclo este mesmo comportamento foi observado no tratamento Ar em ambas as camadas de solo e no tratamento Ad na camada de solo de 0,10 - 0,20 m, nas análises realizadas aos 27 DAT em relação aos 7 e 49 DAT, comportamento este que pode ter sido influenciado pela diferença de absorção pela alface em suas diferentes fases de desenvolvimento (menor na fase inicial e maior na fase final do ciclo), para satisfazer suas necessidades fisiológicas, uma vez que a maioria delas, inclusive a alface, necessita de $\mathrm{S}$ em grandes quantidades, semelhante à necessidade de fósforo.

No tratamento Ad na camada de solo de 0,10 - 0,20 m, ocorreu redução significativa dos 7 aos 49 DAT, chegando a 104\%; o S facilmente sofre redução pelo fato de se trata de um íon facilmente lixiviável no solo. Miranda (1995) também observou redução de S chegando a 43\%, constatando ainda que foi o que sofreu maior lixiviação no solo, dentre os íons analisados.

Condutividade elétrica do solo (EC): Durante o $1^{\circ}$ ciclo notou-se elevação significativa de EC para o tratamento Gbd dos 6 e 26 DAT em relação aos 46 DAT para a camada de solo de 0 - 0,10 m; para a camada de 0,10 - 0,20 m houve redução significativa dos 6 DAT em relação aos 26 e 46 DAT e, no $2^{\circ}$ ciclo, ocorreu redução significativa dos 7 e 27 DAT em relação aos 49 DAT para o tratamento Ad e dos 7 DAT, em relação aos 27 e 49 DAT para o tratamento Gpr, para a camada de solo de 0,10 - 0,20 m (Tabela 4). A condutividade elétrica pode ser influenciada pelo processo de lixiviação de alguns sais no perfil do solo. Caovilla et al. (2005) observaram que o nitrato, o potássio e a concentração total de sais apresentaram 
Tabela 4. Valores médios do cálcio, magnésio, enxofre, condutividade elétrica, matéria orgânica e capacidade de troca de cátions para a irrigação com aspersão, gotejamento subterrâneo e superficial com água residuária e do depósito superficial, para três épocas de coleta de amostra e duas camadas de solo

\begin{tabular}{|c|c|c|c|c|c|c|c|c|c|c|c|c|c|}
\hline \multirow{2}{*}{$\begin{array}{l}\text { Coleta } \\
\text { em DAT }\end{array}$} & \multicolumn{6}{|l|}{$1^{0}$ ciclo } & \multirow{2}{*}{$\begin{array}{l}\text { Coleta } \\
\text { em DAT }\end{array}$} & \multicolumn{6}{|c|}{$2^{0}$ ciclo } \\
\hline & Ar & Ad & Gbr & Gbd & Gpr & Gpd & & Ar & Ad & Gbr & Gbd & Gpr & Gpd \\
\hline \multicolumn{14}{|c|}{ Camada 0-0,10 Cálcio (mg dm-3) } \\
\hline 6 & $4,4 \mathrm{a}$ & $3,7 \mathrm{~b}$ & $4,9 \mathrm{a}$ & $3,4 \mathrm{a}$ & $4,4 \mathrm{a}$ & $4,2 \mathrm{a}$ & 7 & $4,3 \mathrm{a}$ & $4,9 \mathrm{a}$ & $4,6 \mathrm{a}$ & $3,6 \mathrm{a}$ & $4,9 \mathrm{a}$ & $4,2 \mathrm{a}$ \\
\hline 26 & $4,2 \mathrm{a}$ & $4,5 \mathrm{a}$ & $4,5 \mathrm{a}$ & $3,8 \mathrm{a}$ & $4,5 \mathrm{a}$ & $3,7 \mathrm{a}$ & 27 & $4,5 \mathrm{a}$ & $5,2 \mathrm{a}$ & $4,6 \mathrm{a}$ & $3,7 \mathrm{a}$ & $5,0 \mathrm{a}$ & $4,4 \mathrm{a}$ \\
\hline 46 & $4,3 \mathrm{a}$ & $4,6 \mathrm{a}$ & $4,7 \mathrm{a}$ & $3,6 \mathrm{a}$ & $4,4 \mathrm{a}$ & $3,7 \mathrm{a}$ & 49 & $4,6 \mathrm{a}$ & $5,0 \mathrm{a}$ & $4,2 \mathrm{a}$ & $4,0 \mathrm{a}$ & $4,5 \mathrm{a}$ & $4,5 \mathrm{a}$ \\
\hline \multicolumn{14}{|c|}{ Camada $0,10-0,20 \mathrm{~m}$} \\
\hline 6 & $4,2 \mathrm{a}$ & $3,8 \mathrm{~b}$ & $4,3 \mathrm{a}$ & $3,6 \mathrm{a}$ & $4,3 \mathrm{a}$ & $4,3 \mathrm{a}$ & 7 & $4,4 \mathrm{a}$ & $4,9 \mathrm{a}$ & $4,9 \mathrm{a}$ & $3,5 \mathrm{a}$ & $5,2 \mathrm{a}$ & $4,0 \mathrm{a}$ \\
\hline 26 & $3,9 \mathrm{a}$ & $4,3 \mathrm{ab}$ & $5,1 \mathrm{a}$ & $3,2 \mathrm{a}$ & $4,4 \mathrm{a}$ & $3,5 \mathrm{a}$ & 27 & $4,4 \mathrm{a}$ & $4,9 \mathrm{a}$ & $4,8 \mathrm{a}$ & $3,6 \mathrm{a}$ & $4,8 \mathrm{a}$ & $4,2 \mathrm{a}$ \\
\hline 46 & $4,2 \mathrm{a}$ & $4,8 \mathrm{a}$ & $4,2 \mathrm{a}$ & $3,6 \mathrm{a}$ & $4,5 \mathrm{a}$ & $3,9 \mathrm{a}$ & 49 & $4,7 \mathrm{a}$ & $4,9 \mathrm{a}$ & $4,5 \mathrm{a}$ & $3,6 \mathrm{a}$ & $4,5 \mathrm{a}$ & $5,1 \mathrm{a}$ \\
\hline \multicolumn{14}{|c|}{ Camada 0-0,10 m Magnésio $\left(\mathrm{cmol} \mathrm{dm}^{-3}\right)$} \\
\hline 6 & $1,2 \mathrm{a}$ & $1,2 \mathrm{~b}$ & $1,5 \mathrm{a}$ & $1,2 \mathrm{a}$ & $1,4 \mathrm{a}$ & $1,5 \mathrm{a}$ & 7 & $1,4 \mathrm{a}$ & $1,7 \mathrm{a}$ & $1,7 \mathrm{a}$ & $1,3 \mathrm{a}$ & $1,5 \mathrm{a}$ & $1,5 \mathrm{a}$ \\
\hline 26 & $1,3 \mathrm{a}$ & $1,6 \mathrm{a}$ & $1,8 \mathrm{a}$ & $1,5 \mathrm{a}$ & $1,6 \mathrm{a}$ & $1,5 \mathrm{a}$ & 27 & $1,5 \mathrm{a}$ & $1,7 \mathrm{a}$ & $1,6 \mathrm{a}$ & $1,3 \mathrm{a}$ & $1,5 \mathrm{a}$ & $1,5 \mathrm{a}$ \\
\hline 46 & $1,2 \mathrm{a}$ & $1,5 \mathrm{a}$ & $1,4 \mathrm{a}$ & $1,2 \mathrm{a}$ & $1,4 \mathrm{a}$ & $1,3 \mathrm{a}$ & 49 & $1,5 \mathrm{a}$ & $1,8 \mathrm{a}$ & $1,7 \mathrm{a}$ & $1,5 \mathrm{a}$ & $1,6 \mathrm{a}$ & $1,5 \mathrm{a}$ \\
\hline \multicolumn{14}{|c|}{ Camada $0,10-0,20 \mathrm{~m}$} \\
\hline 6 & $1,2 \mathrm{a}$ & $1,2 \mathrm{~b}$ & $1,7 \mathrm{a}$ & $1,3 \mathrm{a}$ & $1,5 \mathrm{a}$ & $1,5 \mathrm{a}$ & 7 & $1,5 a b$ & $1,7 \mathrm{a}$ & $1,8 \mathrm{a}$ & $1,3 \mathrm{a}$ & $1,8 \mathrm{a}$ & $1,8 \mathrm{a}$ \\
\hline 26 & $1,3 \mathrm{a}$ & $1,5 \mathrm{a}$ & $1,4 \mathrm{a}$ & $1,3 \mathrm{a}$ & $1,5 \mathrm{a}$ & $1,4 \mathrm{a}$ & 27 & $1,4 \mathrm{~b}$ & $1,7 \mathrm{a}$ & $1,7 \mathrm{a}$ & $1,3 \mathrm{a}$ & $1,5 \mathrm{a}$ & $1,5 \mathrm{a}$ \\
\hline 46 & $1,2 \mathrm{a}$ & $1,5 \mathrm{a}$ & $1,3 \mathrm{a}$ & $1,2 \mathrm{a}$ & $1,3 \mathrm{a}$ & $1,2 \mathrm{a}$ & 49 & $1,8 \mathrm{a}$ & $1,8 \mathrm{a}$ & $1,8 \mathrm{a}$ & $1,4 \mathrm{a}$ & $1,7 \mathrm{a}$ & $1,7 \mathrm{a}$ \\
\hline \multicolumn{14}{|c|}{ Camada $0-0,10 \mathrm{~m}$ Enxofre $\left(\mathrm{mg} \mathrm{dm}^{-3}\right)$} \\
\hline 6 & $17,0 \mathrm{a}$ & $22,4 \mathrm{a}$ & $16,5 \mathrm{~b}$ & $17,1 \mathrm{a}$ & $23,5 \mathrm{a}$ & 14,2 a & 7 & $37,2 \mathrm{~b}$ & $20,9 \mathrm{~b}$ & $28,3 \mathrm{a}$ & $27,4 \mathrm{a}$ & $36,7 \mathrm{a}$ & $21,6 \mathrm{a}$ \\
\hline 26 & $16,9 \mathrm{a}$ & $19,9 \mathrm{a}$ & $24,8 \mathrm{a}$ & $14,8 \mathrm{a}$ & $17,1 \mathrm{a}$ & $17,2 \mathrm{a}$ & 27 & $54,4 \mathrm{a}$ & $40,6 a b$ & 55,6 a & 30,0 a & $34,7 \mathrm{a}$ & $25,1 \mathrm{a}$ \\
\hline 46 & 17,6 a & $13,8 \mathrm{a}$ & 15,2 b & $16,5 \mathrm{a}$ & $22,9 \mathrm{a}$ & $18,9 \mathrm{a}$ & 49 & $37,1 \mathrm{~b}$ & 14,2 b & $32,5 \mathrm{a}$ & $23,9 \mathrm{a}$ & $25,9 \mathrm{a}$ & $30,6 \mathrm{a}$ \\
\hline \multicolumn{14}{|c|}{ Camada $0,10-0,20 \mathrm{~m}$} \\
\hline 6 & $15,9 \mathrm{a}$ & $18,5 \mathrm{a}$ & $16,3 \mathrm{a}$ & $17,1 \mathrm{a}$ & $22,7 \mathrm{a}$ & $15,3 \mathrm{a}$ & 7 & $37,3 \mathrm{~b}$ & $28,9 a b$ & $38,8 \mathrm{a}$ & $29,8 \mathrm{a}$ & $46,1 \mathrm{a}$ & $29,5 \mathrm{a}$ \\
\hline 26 & $22,2 \mathrm{a}$ & $23,9 \mathrm{a}$ & $18,1 \mathrm{a}$ & $17,4 \mathrm{a}$ & $20,3 \mathrm{a}$ & $21,3 \mathrm{a}$ & 27 & $51,2 \mathrm{a}$ & $34,5 \mathrm{a}$ & $43,8 \mathrm{a}$ & $31,9 \mathrm{a}$ & $41,0 \mathrm{a}$ & $32,8 \mathrm{a}$ \\
\hline 46 & $15,1 \mathrm{a}$ & $16,7 \mathrm{a}$ & $15,2 \mathrm{a}$ & $16,7 \mathrm{a}$ & $19,3 \mathrm{a}$ & 19,3 a & 49 & 31,2 b & $14,2 \mathrm{~b}$ & $27,5 \mathrm{a}$ & $23,5 \mathrm{a}$ & $25,7 \mathrm{~b}$ & $29,8 \mathrm{a}$ \\
\hline \multicolumn{14}{|c|}{ Camada 0-0,10 m Condutividade elétrica (dS m${ }^{-1}$ ) } \\
\hline 6 & $0,16 \mathrm{a}$ & $0,15 \mathrm{a}$ & $0,19 \mathrm{a}$ & $0,13 \mathrm{~b}$ & $0,20 \mathrm{a}$ & $0,13 \mathrm{a}$ & 7 & $0,24 \mathrm{a}$ & $0,17 \mathrm{a}$ & $0,19 \mathrm{a}$ & $0,16 \mathrm{a}$ & $0,25 \mathrm{a}$ & $0,15 \mathrm{a}$ \\
\hline 26 & $0,15 \mathrm{a}$ & $0,17 \mathrm{a}$ & $0,19 \mathrm{a}$ & $0,12 \mathrm{~b}$ & $0,21 \mathrm{a}$ & $0,13 \mathrm{a}$ & 27 & $0,28 \mathrm{a}$ & $0,28 \mathrm{a}$ & $0,22 \mathrm{a}$ & $0,18 \mathrm{a}$ & $0,23 \mathrm{a}$ & $0,17 \mathrm{a}$ \\
\hline 46 & $0,22 \mathrm{a}$ & $0,19 \mathrm{a}$ & $0,20 \mathrm{a}$ & $0,19 \mathrm{a}$ & $0,27 \mathrm{a}$ & $0,18 \mathrm{a}$ & 49 & $0,22 \mathrm{a}$ & $0,14 \mathrm{a}$ & $0,24 \mathrm{a}$ & $0,23 \mathrm{a}$ & $0,25 \mathrm{a}$ & $0,21 \mathrm{a}$ \\
\hline \multicolumn{14}{|c|}{ Camada $0,10-0,20$ m } \\
\hline 6 & $0,14 \mathrm{a}$ & $0,25 \mathrm{a}$ & $0,25 \mathrm{a}$ & $0,30 \mathrm{a}$ & $0,35 \mathrm{a}$ & $0,20 \mathrm{a}$ & 7 & $0,24 \mathrm{a}$ & $0,24 \mathrm{a}$ & $0,28 \mathrm{a}$ & $0,19 \mathrm{a}$ & $0,34 \mathrm{a}$ & $0,22 \mathrm{a}$ \\
\hline 26 & $0,19 \mathrm{a}$ & $0,26 \mathrm{a}$ & $0,15 \mathrm{a}$ & $0,18 \mathrm{~b}$ & $0,17 \mathrm{~b}$ & $0,18 \mathrm{a}$ & 27 & $0,27 \mathrm{a}$ & $0,25 \mathrm{a}$ & $0,25 \mathrm{a}$ & $0,19 \mathrm{a}$ & $0,25 \mathrm{~b}$ & $0,21 \mathrm{a}$ \\
\hline 46 & $0,18 \mathrm{a}$ & $0,24 \mathrm{a}$ & $0,17 \mathrm{a}$ & $0,19 \mathrm{~b}$ & $0,21 \mathrm{~b}$ & $0,20 \mathrm{a}$ & 49 & $0,20 \mathrm{a}$ & $0,15 \mathrm{~b}$ & $0,22 \mathrm{a}$ & $0,23 \mathrm{a}$ & $0,24 \mathrm{~b}$ & $0,22 \mathrm{a}$ \\
\hline \multicolumn{14}{|c|}{ Camada $0-0,10 \mathrm{~m}$ Matéria orgânica $\left(\mathrm{g} \mathrm{dm}^{-3}\right)$} \\
\hline 6 & $33 \mathrm{a}$ & $30 \mathrm{~b}$ & $34 \mathrm{a}$ & $30 \mathrm{a}$ & $37 \mathrm{a}$ & $29 \mathrm{a}$ & 7 & $35 \mathrm{~b}$ & $37 \mathrm{~b}$ & $37 \mathrm{~b}$ & $36 \mathrm{~b}$ & $38 \mathrm{~b}$ & $36 \mathrm{a}$ \\
\hline 26 & $34 \mathrm{a}$ & $33 \mathrm{~b}$ & $36 \mathrm{a}$ & $30 \mathrm{a}$ & $35 \mathrm{a}$ & $33 \mathrm{a}$ & 27 & $36 \mathrm{~b}$ & $36 \mathrm{~b}$ & $38 \mathrm{~b}$ & $34 \mathrm{~b}$ & $39 \mathrm{~b}$ & $36 \mathrm{a}$ \\
\hline 46 & $40 \mathrm{a}$ & $41 \mathrm{a}$ & $39 \mathrm{a}$ & $37 \mathrm{a}$ & $41 \mathrm{a}$ & $37 \mathrm{a}$ & 49 & $48 \mathrm{a}$ & $45 \mathrm{a}$ & $44 \mathrm{a}$ & $45 \mathrm{a}$ & $50 \mathrm{a}$ & $42 \mathrm{a}$ \\
\hline \multicolumn{14}{|c|}{ Camada $0,10-0,20 \mathrm{~m}$} \\
\hline 6 & $31 \mathrm{a}$ & $30 \mathrm{a}$ & $30 \mathrm{a}$ & $30 \mathrm{a}$ & $35 \mathrm{a}$ & $27 \mathrm{a}$ & 7 & $33 \mathrm{~b}$ & $33 \mathrm{~b}$ & $34 \mathrm{~b}$ & $31 \mathrm{~b}$ & $34 \mathrm{~b}$ & $32 \mathrm{a}$ \\
\hline 26 & $31 \mathrm{a}$ & $30 \mathrm{a}$ & $33 \mathrm{a}$ & $27 \mathrm{a}$ & $32 \mathrm{a}$ & $29 \mathrm{a}$ & 27 & $33 \mathrm{~b}$ & $32 \mathrm{~b}$ & $33 \mathrm{~b}$ & $30 \mathrm{~b}$ & $35 \mathrm{~b}$ & $32 \mathrm{a}$ \\
\hline 46 & $36 \mathrm{a}$ & $37 \mathrm{a}$ & $35 \mathrm{a}$ & $34 \mathrm{a}$ & 36 a & $33 \mathrm{a}$ & 49 & $42 \mathrm{a}$ & $40 \mathrm{a}$ & $40 \mathrm{a}$ & $39 \mathrm{a}$ & $44 \mathrm{a}$ & $36 \mathrm{a}$ \\
\hline \multicolumn{14}{|c|}{ Camada 0-0,10 m Capacidade de troca de cátions $\left(\mathrm{cmol} \mathrm{dm}^{-3}\right)$} \\
\hline 6 & $9,1 \mathrm{a}$ & $8,2 \mathrm{a}$ & $9,5 \mathrm{a}$ & $8,2 \mathrm{a}$ & $9,2 \mathrm{a}$ & $8,6 \mathrm{a}$ & 7 & $9,6 \mathrm{a}$ & $9,9 \mathrm{a}$ & $9,8 \mathrm{a}$ & $8,8 \mathrm{a}$ & $10,2 \mathrm{a}$ & $9,1 \mathrm{a}$ \\
\hline 26 & $9,2 \mathrm{a}$ & $9,2 \mathrm{a}$ & $9,4 \mathrm{a}$ & $8,7 \mathrm{a}$ & $9,5 \mathrm{a}$ & $8,6 \mathrm{a}$ & 27 & $9,7 \mathrm{a}$ & $10,1 \mathrm{a}$ & $9,6 \mathrm{a}$ & $8,8 \mathrm{a}$ & $10,2 \mathrm{a}$ & $9,4 \mathrm{a}$ \\
\hline 46 & $9,3 \mathrm{a}$ & $9,4 \mathrm{a}$ & 9,6 a & $8,8 \mathrm{a}$ & $9,5 \mathrm{a}$ & $8,7 \mathrm{a}$ & 49 & $9,9 \mathrm{a}$ & $10,0 \mathrm{a}$ & $9,5 \mathrm{a}$ & $9,6 \mathrm{a}$ & $9,9 \mathrm{a}$ & $10,2 \mathrm{a}$ \\
\hline \multicolumn{14}{|c|}{ Camada $0,10-0,20 \mathrm{~m}$} \\
\hline 6 & $8,8 \mathrm{a}$ & $8,3 \mathrm{a}$ & $8,9 \mathrm{a}$ & $8,6 \mathrm{a}$ & $9,4 \mathrm{a}$ & $8,7 \mathrm{a}$ & 7 & $9,7 \mathrm{a}$ & $9,8 \mathrm{a}$ & $10,1 \mathrm{a}$ & $8,6 \mathrm{a}$ & $10,6 \mathrm{a}$ & $9,1 \mathrm{a}$ \\
\hline 26 & $8,8 \mathrm{a}$ & $8,7 \mathrm{a}$ & $9,8 \mathrm{a}$ & $8,1 \mathrm{a}$ & $9,3 \mathrm{a}$ & $8,4 \mathrm{a}$ & 27 & $9,5 \mathrm{a}$ & $9,7 \mathrm{a}$ & $9,8 \mathrm{a}$ & $8,6 \mathrm{a}$ & $9,9 \mathrm{a}$ & $9,3 \mathrm{a}$ \\
\hline 46 & $9,2 \mathrm{a}$ & $9,8 \mathrm{a}$ & $9,0 \mathrm{a}$ & $8,7 \mathrm{a}$ & $9,5 \mathrm{a}$ & $9,0 \mathrm{a}$ & 49 & $10,2 \mathrm{a}$ & $9,9 \mathrm{a}$ & $9,6 \mathrm{a}$ & $9,3 \mathrm{a}$ & $9,7 \mathrm{a}$ & $10,8 \mathrm{a}$ \\
\hline
\end{tabular}

Médias seguidas de letras distintas na coluna diferem entre si a nível de $10 \%$ de significância para o teste de Tukey

$\mathrm{Ar}$ - Aspersão com água residuária, Ad - aspersão com água do depósito, Gbr - gotejamento subterrâneo com água residuária, Gbd - gotejamento subterrâneo com água do depósito, Gpr - gotejamento superficial com água residuária e Gpd - gotejamento superficial com água do depósito. DAT - Dias após o transplantio

maior mobilidade em colunas de solo irrigada com água residuária de suinocultura e cultivada com soja.

A interferência nos valores de EC observados pode ter tido influência do Na sobre a dispersão das partículas, que depende do teor total eletrolítico na solução do solo, sendo que o aumento da salinidade reduz o potencial de dispersão do solo devido ao aumento de sodicidade (Jnad et al., 2001).
Matéria Orgânica (MO): No $1^{\circ}$ ciclo, a elevação no teor de MO foi significativa para o tratamento Ad dos 6 e 26 DAT em relação aos 46 DAT na camada de $0-0,10$ m; no $2^{\circ}$ ciclo, este mesmo comportamento foi observado nos tratamentos Ar, Ad, Gbr, Gbd e Gpr dos 7 e 27 DAT em relação aos 49 DAT, em ambas as camadas de solo; os maiores aumentos foram de $37 \%$ nos tratamentos Ad no $1^{\circ}$ ciclo e Ar no $2^{\circ}$ 
ciclo para a camada de solo de 0 - 0,10 m (Tabela 4); esses resultados mostram que a aplicação de efluentes ao solo favoreceu a elevação da MO do solo, concordando com outros autores, como Miranda (1995), que encontrou um acréscimo de $19 \%$ na $\mathrm{MO}$, quando da adição, ao solo, de efluente doméstico tratado com lagoa de estabilização e água límpida de um açude. Baumgartner et al. (2007) encontrou elevação de $68 \%$ nos teores de MO do solo irrigado com água de lagoa de cultivo de algas, alimentada com resíduo de biodigestor de dejeto de suíno.

Capacidade de Troca de Cátions (CTC): Observa-se, no $2^{\circ}$ ciclo, que os teores de CTC foram sempre superiores aos do $1^{\circ}$ ciclo, chegando a $10,8 \mathrm{cmol} \mathrm{dm}^{-3}$ no tratamento Gpd aos 49 DAT na camada de solo de 0,10 - 0,20 m (Tabela 4). O menor valor observado foi de $8,1 \mathrm{cmol} \mathrm{dm}^{-3}$ no $1^{\circ}$ ciclo no tratamento Gbd aos 26 DAT, para a camada de solo de 0,10 - 0,20 m; tem-se no $1^{\circ}$ ciclo e em todos os tratamentos e em ambas as camadas de solo, uma leve tendência de elevação dos teores de CTC dos 6 aos 46 DAT, porém de forma não significativa, chegando a $14,7 \%$ no tratamento Ad.

\section{CONCLUSÕES}

1. O íon sódio foi o que apresentou maior elevação de seu teor no solo no $1^{\circ}$ ciclo, com diferença significativa nos tratamentos Ar, Ad, Gbr e Gpr entre as épocas de coleta de 6 aos 46 DAT, em ambas as camadas de solo.

2. No $1^{\circ}$ ciclo o manganês e o cobre apresentaram elevação na camada de solo de 0-0,10 m irrigada com água residuária nos tratamentos Ar e Gpr.

3 . No $2^{\circ}$ ciclo o solo irrigado com água residuária apresentou elevação do nitrogênio total em ambas as camadas analisadas e a matéria orgânica somente na camada de 0-0,10 m. O manganês e o cobre apresentaram redução, atribuindo-se este fato às chuvas que ocorreram no período.

\section{AGRADECIMENTOS}

À Fundação de Amparo à Pesquisa do Estado de São Paulo, pelo auxílio concedido, e à Faculdade de Engenharia Agrícola, UNICAMP.

\section{LITERATURA CITADA}

Adans, P.; Graves, C. J.; Windson, G. W. Effects of copper deficiency and liming on the yield, quality and copper status of tomatoes, lettuce, and cucumber grown in peat. Scientia Horticultural, v.9, n.3, p.199-205, 1979.

Ayers, R. S.; Westcot, D. W. A qualidade da água na agricultura. 2.ed. Campina Grande: UFPB, 1991. 218p. Estudos da FAO: Irrigação e Drenagem, 29 Revisado 1.

Baumgartner, D.; Sampaio, S. C.; Silva, T. R.; Teo, C. R. T. A.; Vilas Boas, M. A. Reúso de águas residuárias da piscicultura e da suinocultura na irrigação da cultura da alface. Engenharia Agrícola, v.27, n.1, p.152-163, 2007.
Biscaro, G. A. Utilização de águas receptoras de efluentes urbanos em sistemas de irrigação localizada superficial e subsuperficial na cultura da alface americana (Lactuca sativa L.). Botucatu: FCA/UNESP, 2003. 130p. Tese Doutorado

Borkert, C. M.; Pavan, M. A.; Bataglia, O. C. Disponibilidade e avaliação de elementos catiônicos: ferro e manganês. In: Pereira, M. E.; Cruz, M. C. P.; Raij, B. van; Abreu, C. A. Micronutrientes e elementos tóxicos na agricultura. Jaboticabal: CNPq/FAPESP/POTAFOS, 2001. p.151-185.

Caovilla, F. A.; Sampaio, S. C.; Pereira, J. O.; Vilas Boas, M. A.; Gomes, B.; Figueirêdo, A. C. Lixiviação de nutrientes provenientes de águas residuárias em colunas de solo cultivado com soja. Revista Brasileira de Engenharia Agrícola e Ambiental, v.9 (suplemento), p.283-287, 2005.

Cavallet, E. E.; Lucchesi, L. A. C.; Moraes, A.; Schimidt, E.; Perondi, M. A.; Fonseca, R. A. Melhoria da fertilidade do solo decorrentes da adição de água residuária da indústria de enzimas. Revista Brasileira de Engenharia Agrícola e Ambiental, v.10, n.3, p.724-729, 2006.

Cerqueira, L. L.; Fadigas, F. S. Pereira, F. A.; Gloaguen, T. V.; Costa, J. A. desenvolvimento de Heliconia psittacorum e Gladiolus hortulanus irrigados com águas residuárias tratadas. Revista Brasileira de Engenharia Agrícola e Ambiental, v.12, n.6, p.606-613, 2008.

Costa, J. P. V.; Barros, N. F.; Bastos, A. L.; Albuquerque, A. W. Fluxo difusivo de potássio em solos sob diferentes níveis de umidade e de compactação. Revista Brasileira de Engenharia Agrícola e Ambiental, v.13, n.1, p.56-62, 2009.

Crook, J. Quality criteria for reclaimed water. Water Science and Technology, v.24, n.9, p.109-121, 1991.

Duarte, A. S.; Airoldi, R. P. S.; Folegatti, M. V.; Botrel, T. A. Soares, T. M. Efeitos da aplicação de efluente tratado no solo: pH, matéria orgânica, fósforo e potássio. Revista Brasileira de Engenharia Agrícola e Ambiental, v.12, n.3, p.302-310, 2008.

Heidarpour, M.; Mostafazadeh-Fard, B.; Abedi Koupai, J.; Malekian, R. The effects of treated wastewater on soil chemical properties using subsurface and surface irrigation methods. Agricultural Water Management, v.90, n.1-2, p.87-94, 2007.

Hespanhol, I. Potencial de reúso de água no Brasil: Agricultura, indústria, município e recarga de aqüíferos. In: Mancuso, P. C. S.; Santos, H. F. Reúso de água. São Paulo: Faculdade de Saúde Pública/Universidade de São Paulo, 2003. p.37-95.

Jnad, I.; Lesikar, B.; Kenimer, A.; Sabbagh, G. Subsurface drip of residential effluent: I. soil chemical characteristics. Transaction of the ASAE, v.44, n.5, p.1149-1157, 2001.

Kiziloglu, F. M.; Turan, M.; Sahin, U.; Kuslu, Y.; Dursun, A. Effects of untreated and treated wastewater irrigation on some chemical properties of cauliflower (Brassica olerecea L. var. botrytis) and red cabbage (Brassica olerecea L. var. rubra) grown on calcareous soil in Turkey. Agricultural Water Management, v.95, n.6, p.716-724, 2008.

Lima, L. A.; Grismer, M. E.; Nielsen, D. R. Salinity effect on yolo loam hydraulic properties. Soil Science, v.150, n.1, p.451-458, 1990.

Lisbão, R. S.; Nagai, H.; Trani, P. E. Alface. In: Instruções agrícolas para o estado de São Paulo. 5.ed. Revisada e atualizada. Boletim 200. Campinas: Instituto Agronômico de Campinas, 1990. 233p.

R. Bras. Eng. Agríc. Ambiental, v.13, n.6, p.755-764, 2009. 
Madeira, C. A.; Peña, M. R.; Mara, D. D. Microbiological quality of a waste stabilization pond effluent used for restricted irrigation in Valle Del Cauca, Colombia. Water Science and Technology, v.45, n.1, p.139-143, 2002.

Medeiros, S. S.; Soares, A. A.; Ferreira, P. A.; Neves, J. C. L.; Matos, A. T.; Souza, J. A. A. Utilização de água residuária de origem doméstica na agricultura: Estudo das alterações químicas do solo. Revista Brasileira de Engenharia Agrícola e Ambiental, v.9, n.4, p.603-612, 2005b.

Medeiros, S. S.; Soares, A. A.; Ferreira, P. A.; Souza, J. A. A.; Souza, J. A.; Matos, A. T. Comportamento dos atributos químicos do solo em resposta à aplicação de água residuária de origem doméstica. Revista Brasileira de Engenharia Agrícola e Ambiental, v.9 (suplemento), p.268-273, 2005a.

Miranda, T. L. G. Reúso de efluente de esgoto doméstico na irrigação de alface (Lactuca sativa L.). Porto Alegre: Instituto de Pesquisas Hidráulicas/UFRGS, 1995. 109p. Dissertação Mestrado

Miranda, F. R.; Lima, R. N.; Crisóstomo, L. A.; Santana, M. G. S. Reuse of inland low-salinity shrimp farm effluent for melon irrigation. Aquacultural Engineering, v.39, n.1, p.1-5, 2008.
Neilsen, G. H.; Stevenson, D. S.; Fitzpatrick, J. J.; Brownlle, C. $\mathrm{H}$. Yield and plant nutrient content of vegetbles trickle-irrigated with municipal wastewater. HortScience, v.24, n.2, p.249-252, 1989.

Paganini, W. S. Disposição de esgotos no solo: escoamento à superfície. São Paulo: AESABESP, 1997. 232p.

Silva, F. B. Manual de análises químicas de solos, plantas e fertilizante. Brasília: Embrapa Comunicação para Transferência de Tecnologia, 1999. 370p.

Silva, V. F.; Sousa, J. T.; Vieira, F. F.; Santos, K. D. Tratamento anaeróbio de esgoto doméstico para fertirrigação. Revista Brasileira de Engenharia Agrícola e Ambiental, v.9, n.suplemento, p.186-190, 2005.

Trani, P. E. Hortaliças folhosas e condimentos. In: Pereira, M. E.; Cruz, M. C. P.; Raij, B. van; Abreu, C. A. Micronutrientes e elementos tóxicos na agricultura. Jaboticabal: CNPq/FAPESP/ POTAFOS, 2001. p.293-510.

Trani, P. E.; Raij, B. van. Hortaliças. 2.ed. Campinas: IAC, 1997. p.30-36. Boletim Técnico 100

von Sperling, M. Princípios de tratamento biológico de águas residuárias. Belo Horizonte: UFMG, 2ed., v.2, 1996. 243p. 